\title{
Analysis of Recent Development of Spectrum Auction and Forecast of Future Development
}

\author{
Shuner $\mathrm{Hu}^{1, * \dagger}$, Ruhua $\mathrm{Shi}^{2, \dagger}$ \\ ${ }^{1}$ The University of Warwick, Coventry CV4 7AL, United Kingdom \\ ${ }^{2}$ Hangzhou No.4 High School International School, Hangzhou, China \\ *Corresponding author. Email: 'Shuner.Hu@warwick.ac.uk \\ ${ }^{\dagger}$ These authors contributed equally.
}

\begin{abstract}
Based on the operating mechanism of the spectrum auction, this paper analyzes the bidder's quotation mechanism in the spectrum auction process from both qualitative and quantitative perspectives from the perspective of the $5 \mathrm{G}$ basic spectrum. At the same time, they are taking the Canadian spectrum auction as an example, combining actual data to explore the spectrum auction's development process and action mechanism. Studies have shown that spectrum auctions will become an effective tool for people to use higher frequencies as buying and selling spectrum and estimation capabilities in the future, which will help voters achieve the highest benefits.
\end{abstract}

Keywords: Spectrum Auction, Recent Development, Forecast, Future Development.

\section{INTRODUCTION}

\subsection{Research Background and Motivation}

The first spectrum auction was held in New Zealand in 1989. Thirty-three spectrum auctions were conducted in the United States from July 1994 to February 2001, and a $3 \mathrm{G}$ license auction was launched in Europe in 20002001. In 1994, the first simultaneous auctions were held in the United States. In 1999. Canada held the first spectrum auction, followed by a second in 2001. In 2000, the United States, Germany, Italy and others improved their spectrum auction system. In the same year, auctions were used for the first time in Britain to allocate frequencies. In 2002, Professor MartinCave of the UK submitted a report to the government, arguing that the UK needs to fundamentally change the way of frequency management, that is, the economic mechanism of management should mainly include the frequency trading system, frequency liberalization, and the auction system of idle frequencies. The government subsequently adopted the report. And to some extent, it contributed to the introduction of the 2003 UK Telecommunications Act. Nigeria awarded three GSM spectrum licences in January 2001 using a mixed auction (clock phase and closed bid phase). In general, spectrum auctions are widely used in Europe and the United States. Most of the spectrum auctions in European countries have borrowed and followed the British spectrum auction strategy.
The Italian 5G spectrum auction in October 2020 led the entire telecom industry to focus on the activity of the German spectrum auction. Italian mobile service providers (MsPs) paid $€ 6.55$ billion for $5 \mathrm{G}$ spectrum. Germany, Europe's largest economy, has just completed its record-breaking 497 auctions of $5 \mathrm{G}$ spectrum. Based on the recent $5 \mathrm{G}$ spectrum auction, the potential for enterprise verticals, and the surge in consumer data traffic over the next decade, interest in the $5 \mathrm{G}$ spectrum is higher than any other telecom product before it. On October 12, 2020, the Nobel Prize in economics was awarded to Robert Wilson and Paul Milgrom of Stanford University. They "improved the auction theory, invented a new way of auction", the use of a synchronous rounds "auction", solve the problem of the radio spectrum auction, the auction theory is proved by the successful cases, the unification of the theory and practice, the Nobel Prize in economics can more practical guiding significance and practical problem-solving. Based on this award is due to the communication industry, the communication show person popularizes the "synchronous multi-round auction", many people do not know this auction method, in fact, this thing can guide the communication industry business transaction, many industries can also be applied. "Simultaneous multi-round auction", also known as "simultaneous increase auction". In this mechanism, all spectrum was put up for sale at the same time, the bidders to seal form to one or more of the price spectrum offer, after the end of each round only released each spectrum 
received the highest price, as the next round of the auction starting price, which didn't get a higher bid price until all the spectrum after all auctions end at the same time. In that process, bidders could withdraw some or all of their offers and instead bid for alternative spectrum at lower prices.

\subsection{Literature Review}

This chapter reviews the key literature concerned with the current design and some data analysis done by previous scholars, with predicting its future developing trend. Given that the spectrum is a scarce resource and has been used in many aspects such as telecommunication, this part will mention and state other scholars' findings and conclusions. According to Wang, $\mathrm{J}$ and other 4 scholars, they claimed that the potential menace exists due to the semi-honest agent that complete the auction process. Privacy reveals of bidders and the possibility of collusion to manipulate the whole auction led to the scholars' design of a secure spectrum auction protocol, and they finally did theoretical analysis and simulation experiments of it [1]. Similarly, a model designed by Dong, $\mathrm{X}$, and the other 5 scholars, also made the auction system more reliable. They successfully handled the issue in which attackers followed an equalsum rule rather than their true appraisals before this design. Using theories and the numerical result, they proved that [2]. Devi, M., Sarma, N., \& Deka, S. K. proposed a single-sided sealed-bid sequential-biddingbased auction framework. The current existing auction designs primarily aim at revenue maximization for auctioneers, due to which certain CR constraints remain excluded in their models. Still, they addressed two such constraints and tested the validity [3].

\subsection{Research Contents and Framework}

Based on this, this paper makes theoretical and empirical analysis of the development status of spectrum auction, and selects the United States, The European Union and other countries as the standard to compare with the previous spectrum auction situation, and combines the actual situation of the current spectrum auction to optimize the auction mechanism. The framework of this paper is arranged as follows: The first part is introduction; the second part is theoretical and empirical analysis; the third part is the result and discussion based on theoretical and empirical analysis; the fourth part is the conclusion.

\section{METHODOLOGY}

\subsection{Empirical}

\subsubsection{Data Source}

The data sources of this paper are mainly from
Google, Baidu Scholar and Google Scholar websites. The sample data are all from 2019 to 2021 (there is also a comparison result with 2016) to ensure the validity of the content. In this paper, examples will be cited to introduce the frequency bands captured by various countries and the final auction prices for further analysis.

\subsubsection{Data Analysis}

Take the spectrum auction that took place on 12th August 2021. For instance, it can be seen from the table that $700 \mathrm{MHz}$ and $2500 \mathrm{MHz}$ spectrum is not auctioned. $700 \mathrm{MHz}$ spectrum is regarded as one of the best $5 \mathrm{G}$ internet time below $1 \mathrm{GHz}$ spectrum, but due to its high price, this section was not auctioned in October in 2016 auction. $2300 \mathrm{GHz}$ sold the most $(89.3 \%)$, followed by $800 \mathrm{GHz}$ section $(65.2 \%)$, then $1800 \mathrm{GHz}(42.9 \%)$, $900 \mathrm{GHz}$ section $(38.9 \%)$ and finally $15 \mathrm{GHz}$ spectrum $(8.6 \%)$. Therefore, $37 \%$ of the whole spectrum will be sold in May 2021, and the government will generate 77.815 billion rupees.

Table 1. Quantity of spectrum sold and put to auction in March 2021

\begin{tabular}{llll}
\hline Band & $\begin{array}{l}\text { Quantity put } \\
\text { to the } \\
\text { auction } \\
(\mathrm{MHz})\end{array}$ & $\begin{array}{l}\text { The } \\
\text { quantity } \\
\text { acquired } \\
(\mathrm{MHz})\end{array}$ & Percentage \\
\hline $700 \mathrm{MHz}$ & 0 & 0 & 0 \\
$800 \mathrm{MHz}$ & 230 & 150 & 65.2 \\
$900 \mathrm{MHz}$ & 98.8 & 38.4 & 38.9 \\
$1800 \mathrm{MHz}$ & 355 & 152.2 & 42.9 \\
$2100 \mathrm{MHz}$ & 175 & 15 & 8.6 \\
$2300 \mathrm{MHz}$ & 560 & 500 & 89.3 \\
$2500 \mathrm{MHz}$ & 230 & 0 & 0 \\
Total & 2308.8 & 855.6 & 37.1 \\
\hline
\end{tabular}

\subsubsection{Canada Spectrum Auction and American Spectrum Auction}

OTTAWA, July 29 (Reuters) - Canada's auction of $3500 \mathrm{MHz}$ spectrum, which is key for next-generation 5G networks, generated a record C\$8.9 billion ( $\$ 7.2$ billion, where $\$ 1=1.2181$ Canadian dollars), with the country's three dominant telecommunication companies accounting for more than $80 \%$ of the amount raised. Out of 1,504 available licenses, 1,495 were awarded to 15 Canadian companies, including 757 licenses to small and regional providers, Innovation Minister FrancoisPhilippe Champagne said in a statement on Thursday. He adds that the result would stimulate competition. A case in point is that Ottawa's push to open up a market dominated by BCE Inc (BCE.TO), Telus Corp (T.TO) and Rogers Communications Inc (RCIb.TO), known as the big three. Local consumers are complaining about the high wireless bills to be paid, which are among the highest in the world, and Prime Minister Justin Trudeau's Liberal government has asked operators to cut prices by 
a quarter by 2021 . Preliminary results showed that BCE Inc spent $\mathrm{C} \$ 2.1$ billion, Rogers $\mathrm{C} \$ 3.3$ billion and Telus Corp C\$1.9 billion. The $3500 \mathrm{MHz}$ range airwaves are key to providing $5 \mathrm{G}$ wireless services due to their advantage in carrying larger data volumes over a long distance. They also improved the pace of downloading and uploading to help power everything from smart cities to drive-less car uses. Vidéotron, the owner of Quebecor Inc (QBRb.TO), spent C\$830 million to expand its geographic footprint in Canada, buying licenses in its native Quebec and other regions in Ontario Manitoba, Alberta and British Columbia. The move indicates that Quebecor has the intention to become a service provider in those areas, said Mark Goldberg, an industry analyst. He noted that the areas where the company did not bid Saskatchewan and Atlantic Canada, which both have preexisting strong fourth competitors to the big three. "They are prepared to be the fourth service provider. This is showing pretty close to a billion dollars in investment in the spectrum," Goldberg said. Vidéotron added that the investment would help the company to "realize its ambition of boosting healthy competition in telecom beyond the borders of Québec." The common practice of European and American governments is to conduct spectrum auctions to determine the price of spectrum in a market way. In the spectrum auction in the United States, the four major operators and dozens of small regional telecom operators can participate and even resell the spectrum second-hand. An auction can create billions or even tens of billions of dollars in fiscal revenue for the government. The auctions in the United States since 2016 have been millimeter wave bands, and the price is relatively lower than that of bands below $2.7 \mathrm{GHz}$. This is because the $5 \mathrm{G}$ sub- $6 \mathrm{GHz}$ band in the United States is occupied, and the construction of a $5 \mathrm{G}$ network in a millimeter wave band is very inefficient and uneconomical. Operators are not optimistic about the economic effects of these frequency bands, so they did not spend a lot of money to bid. The United States spent a lot of time and energy cleaning up the sub-6ghz band before it was able to start auctioning new $3.5 \mathrm{GHz}$ and 3.7 GHz bands in the second half of 2020. The most striking one is the $3.7 \mathrm{GHz}$ band, which coincides with the $5 \mathrm{G} \mathrm{n} 77$ band in other countries. If the auction is completed, $5 \mathrm{~g}$ networks comparable to other countries can be quickly laid, resulting in huge economic benefits. It is estimated that the total auction revenue will exceed $\$ 60$ billion, becoming the most expensive band in history. Potential problems arise as most European and Asian countries have completed $5 \mathrm{~g}$ spectrum allocation in 2018 and 2019. The United States will not start the auction until the second half of 2020 , not counting that the auction will take several months. This leads to the commercial of $5 \mathrm{~g}$ if in the United States at least two years later. Most of these countries have allocated at least a 300 $\mathrm{MHz}$ spectrum to apply $5 \mathrm{G}$ technology, and each supplier has obtained at least a $100 \mathrm{MHz}$ spectrum. For example, China's three major operators and radio and television each obtain $100 \mathrm{MHz}$ spectrum in N78 and N79 channels. The CBRS 3.5GHz (LTE band 48) band to be auctioned in the United States in June 2020 only provides a $70 \mathrm{MHz}$ spectrum and needs to be shared with the U.S. military. Compared with other countries, the $5 \mathrm{G}$ spectrum capacity is rather limited. To obtain more $5 \mathrm{G}$ spectrum, the US hopes to reallocate C-band $3.7 \mathrm{GHz}$. Satellite TV manufacturers have occupied this part of the frequency band, and the FCC is now bargaining with these manufacturers to hold an auction of this part of the spectrum before the end of 2020 .

\subsubsection{2021 Spectrum Auction}

By constructing a spectrum auction matrix, 'the user's organization and the potential competitors are listed, and they are ranked with respect to each evaluation criteria. If the organization is the only one that programs in the desired language, then it will likely receive the highest rank. Lastly, a score is provided by multiplying the assigned weight by the rank concerning each evaluation criteria. The scores illustrate the competitiveness of each bidder as it relates to issues that concern the customer. Table 2 and Table 3 show the results of two companies Bharti Airtel Limited and Reliance Jio Infocomm's spectrum auction launched in 2021, which all concluded in the Bidding matrix for the $800 \mathrm{MHz}$ band. There are 6 rounds of the auction in total, and the total number of blocks bid is embedded and is $1.25 \mathrm{MHz}$ each. In the matrix, 0 means they did not have an auction, and as for the remaining numbers, they are their bids. As shown in the matrix, both companies finished their bid at the first round and with Reliance Jio Infocomm bid is apparently more countries and with higher bids.

Table 2. Bidding Matrix (800 MHz) Bharti Airtel Limited

\begin{tabular}{cllllll}
\hline Service area & 1 & 2 & 3 & 4 & 5 & 6 \\
\hline Andhrad Pradesh & 0 & 0 & 0 & 0 & 0 & 0 \\
Assam & 0 & 0 & 0 & 0 & 0 & 0 \\
Bihar & 0 & 0 & 0 & 0 & 0 & 0 \\
Delhi & 0 & 0 & 0 & 0 & 0 & 0 \\
Gujarat & 0 & 0 & 0 & 0 & 0 & 0 \\
Haryana & 3 & 0 & 0 & 0 & 0 & 0 \\
HimachalPradesh & 0 & 0 & 0 & 0 & 0 & 0 \\
Jammu\&Kashmir & 0 & 0 & 0 & 0 & 0 & 0 \\
Karnataka & 0 & 0 & 0 & 0 & 0 & 0 \\
Kerala & 0 & 0 & 0 & 0 & 0 & 0 \\
Klokata & 0 & 0 & 0 & 0 & 0 & 0 \\
MadhyaPradesh & 4 & 0 & 0 & 0 & 0 & 0 \\
Maharashtra & 2 & 0 & 0 & 0 & 0 & 0 \\
Mumbai & 0 & 0 & 0 & 0 & 0 & 0 \\
North East & 0 & 0 & 0 & 0 & 0 & 0 \\
Odisha & 0 & 0 & 0 & 0 & 0 & 0 \\
Punjab & 0 & 0 & 0 & 0 & 0 & 0 \\
Rajasthan & 0 & 0 & 0 & 0 & 0 & 0 \\
Tamil Nadu & 0 & 0 & 0 & 0 & 0 & 0 \\
Uttar Pardesh & 0 & 0 & 0 & 0 & 0 & 0 \\
(East) & & & & & & \\
Uttar Pardesh & 4 & 0 & 0 & 0 & 0 & 0 \\
(West) & & & & & & \\
West Bengal & 0 & 0 & 0 & 0 & 0 & 0 \\
\hline & & & & & &
\end{tabular}


Table 3. Bidding Matrix (800MHz) Reliance Jio Infocomm

\begin{tabular}{cllllll}
\hline Service area & 1 & 2 & 3 & 4 & 5 & 6 \\
\hline Andhrad Pradesh & 0 & 0 & 0 & 0 & 0 & 0 \\
Assam & 4 & 0 & 0 & 0 & 0 & 0 \\
Bihar & 7 & 0 & 0 & 0 & 0 & 0 \\
Delhi & 4 & 0 & 0 & 0 & 0 & 0 \\
Gujarat & 4 & 0 & 0 & 0 & 0 & 0 \\
Haryana & 4 & 0 & 0 & 0 & 0 & 0 \\
HimachalPradesh & 4 & 0 & 0 & 0 & 0 & 0 \\
Jammu\&Kashmir & 0 & 0 & 0 & 0 & 0 & 0 \\
Karnataka & 8 & 0 & 0 & 0 & 0 & 0 \\
Kerala & 8 & 0 & 0 & 0 & 0 & 0 \\
Klokata & 8 & 0 & 0 & 0 & 0 & 0 \\
MadhyaPradesh & 4 & 0 & 0 & 0 & 0 & 0 \\
Maharashtra & 8 & 0 & 0 & 0 & 0 & 0 \\
Mumbai & 6 & 0 & 0 & 0 & 0 & 0 \\
North East & 0 & 0 & 0 & 0 & 0 & 0 \\
Odisha & 4 & 0 & 0 & 0 & 0 & 0 \\
Punjab & 5 & 0 & 0 & 0 & 0 & 0 \\
Rajasthan & 4 & 0 & 0 & 0 & 0 & 0 \\
Tamil Nadu & 8 & 0 & 0 & 0 & 0 & 0 \\
Uttar Pardesh & 4 & 0 & 0 & 0 & 0 & 0 \\
(East) & & & & & & \\
Uttar Pardesh & 4 & 0 & 0 & 0 & 0 & 0 \\
(West) & & & & & & \\
West Bengal & 8 & 0 & 0 & 0 & 0 & 0 \\
\hline & & & & & &
\end{tabular}

\subsubsection{Bangladesh $4 G$ Auction}

The country held its first $4 \mathrm{G}$ spectrum auction in early 2018. GSMA Intelligence data showed 4G connections increased 70 per cent year-on-year to 27 million in 2020 , with penetration up from 9.7 per cent in 2019 to 16 per cent, showing significant progress. The spectrum licenses have 15 -year terms, with operators required to pay 25 per cent by 23 March and the remainder in installments over five years. In April 2020, the operators called on BTRC to release an additional $2100 \mathrm{MHz}$ spectrum as they experienced a surged in data usage during a Covid-19 (coronavirus) lock-down. Operators in Bangladesh spent $\$ 898.2$ million to secure spectrum in the $1800 \mathrm{MHz}$ and $2100 \mathrm{MHz}$ bands and to expand their limited $4 \mathrm{G}$ holdings to ensure the surge in data service demands. The Bangladesh Telecommunications Regulatory Commission (BRTC) auctioned four $5 \mathrm{MHz}$ blocks in the $2100 \mathrm{MHz}$ band and $7.4 \mathrm{MHz}$ of $1800 \mathrm{MHz}$ spectrum. It is now known that Grameenphone spent $\$ 391.8$ million on $10 \mathrm{MHz}$ of $2100 \mathrm{MHz}$ and $0.4 \mathrm{MHz}$ of $1800 \mathrm{MHz}$ airwaves, bringing its total holdings to $47.4 \mathrm{MHz}, 20 \mathrm{MHz}$ of which is in the $2100 \mathrm{MHz}$ band. Robi Axiata acquired $5 \mathrm{MHz}$ of $2100 \mathrm{MHz}$ and $2.6 \mathrm{MHz}$ of $1800 \mathrm{MHz}$ band for $\$ 225.6$ million, while Banglalink bought $5 \mathrm{MHz}$ of $2100 \mathrm{MHz}$ and $4.4 \mathrm{MHz}$ of $1800 \mathrm{MHz}$ for $\$ 281.4$ million so that they each now have $15 \mathrm{MHz}$ of $2100 \mathrm{MHz}$ spectrum. All three increased their individual holdings in the $1800 \mathrm{MHz}$ band to $20 \mathrm{MHz}$. In a statement to Grameenphone acting CEO and CFO, Jens Becker told MWL the additional spectrum that could further contribute to the digitized time for Bangladesh and ensure people's growing demand for high-speed internet in rural and urban areas. He emphasizes they will keep enhancing the $4 \mathrm{G}$ quality of service by focusing on widespread coverage.

\section{RESULT AND DISCUSSION}

The results obtained by the method adopted in the second part are analyzed and interpreted objectively. At the same time, the similarities and differences between the research results of this paper and other research results are analyzed in an attempt to give future research directions. Spectrum auction to explore the future development path, this paper respectively from two aspects of theory and practice has carried on the detailed description, in theory, based on the existing research results, this paper from the historical development of spectrum auction, spectrum auction rules of structure, the difference between the spectrum auction and other auction and competitiveness of the influence of spectrum auction and development are analyzed in theory. Datawise, it is concluded in this paper that spectrum is a highly scarce resource, and each band has its own use. Looking at the world at large, the lower the band, the lower the price. $800 \mathrm{MHz}$ and $2300 \mathrm{MHz}$ bands are mostly auctioned, especially the latter, with $65.2 \%$ and almost $90 \%$ respectively are being auctioned. The case in Canada show $3500 \mathrm{MHz}$ as their key for the $5 \mathrm{G}$ development, generated C\$8.9 billion for the country. America seems less pleasant in auctioning both lower and upper bands, and a new bidding strategy is required for them to be put into practice. Two coorporations, Bharti Airtel Limited and Reliance Jio Infocomm, countries worldwide, all finished their bids in the first round, indicate the scarce and huge use of spectrum.

\section{CONCLUSION}

As for the summary and summary of the full text, echoing the full text, the existing problems and solutions of Spectrum Auction are explained, and the advantages and disadvantages of spectrum Auction in the current state are summarized. After showing how useful the spectrum is and how much benefit it can bring to society, we propose our own assumptions and inferences about its future development and prospects. It will indicate our ultimate purpose, who needs to care about the topic, the importance of our research and its future trends. Technically speaking, $5 \mathrm{G}$ can be used in each kind of band, low frequency, medium frequency and high frequency. Empirical aspect, this paper selected the European Union and the United States in recent years development data in the data analysis, it is found that the spectrum auction in the current auction market advantages and advanced nature, the second is spectrum auction market is developing rapidly, the third is based on the original frame of spectrum auction will be combined with the development of more advanced computing mechanism and model of the computer program. 


\section{REFERENCES}

[1] Wang, J., Lu, N., Cheng, Q., Zhou, L., \& Shi, W. (2021). A secure spectrum auction scheme without the trusted party based on the smart contract. Digital Communications and Networks, 7(2), 223-234.

[2] Dong, X., Zhang, Y., Guo, Y., Gong, Y., Shen, Y., \& Ma, J. (2021). PRAM: a Practical Sybil-Proof Auction Mechanism for Dynamic Spectrum Access with Untruthful Attackers. IEEE Transactions on Mobile Computing.

[3] Devi, M., Sarma, N., \& Deka, S. K. (2021). MultiWinner Spectrum Allocation in Cognitive Radio Networks: A Single-Sided Auction Theoretic Modelling Approach with Sequential Bidding. Electronics 2021, 10, 602.

[4] Joseph, K., \& McNally, M. B. (2021). Rural vs Urban vs 5G: An Analysis of Canadian $3500 \mathrm{MHz}$ Spectrum Auction Consultations.

[5] Matinmikko-Blue, M., Yrjölä, S., Seppänen, V., Ahokangas, P., Hämmäinen, H., \& Latva-Aho, M. (2019). Analysis of spectrum valuation elements for local 5G networks: Case study of $3.5-\mathrm{GHz}$ band. IEEE Transactions on Cognitive Communications and Networking, 5(3), 741-753.

[6] Sridhar, V., \& Prasad, R. (2021). Analysis of spectrum pricing for commercial mobile services: A cross country study. Telecommunications Policy, 102221.

[7] Srinuan, C., \& Srinuan, P. (2021). Determining spectrum caps and service efficiency: A case study of mobile operators in Thailand. Telecommunications Policy, 102225. 